\title{
Gel immersion technique for the examination and treatment of an ampullary tumor
}

Endoscopic papillectomy using the underwater technique [1] for ampullary tumors allows for involutions of the mucosal folds and permits resection without capturing the muscularis propria and without the need for submucosal fluid injection [2,3]. However, there are some disadvantages to underwater endoscopic papillectomy. For example, it can be difficult to maintain a sufficient amount of water, there is a risk of flushing away the resected specimens, and mixing of any blood with the water can cause loss of visibility. To overcome these disadvantages, we successfully applied the gel immersion technique, a novel method for securing the endoscopic visual field using gel with an appropriate viscosity (Viscoclear; Otsuka Pharmaceutical Factory, Inc., Tokushima, Japan) during gastrointestinal tract bleeding [4, 5].

A 67-year-old man presented with an ampullary tumor ( $\triangleright$ Fig.1) and endoscopic ultrasonography (EUS) was performed. Gel immersion EUS (Gl-EUS) provided better acoustic coupling without flattening of the tumor, for a longer time than with water filling, and revealed an ampullary tumor without invasion of the duodenal muscularis propria or intraductal involvement (>Fig. 2; Video 1). GI-EUS

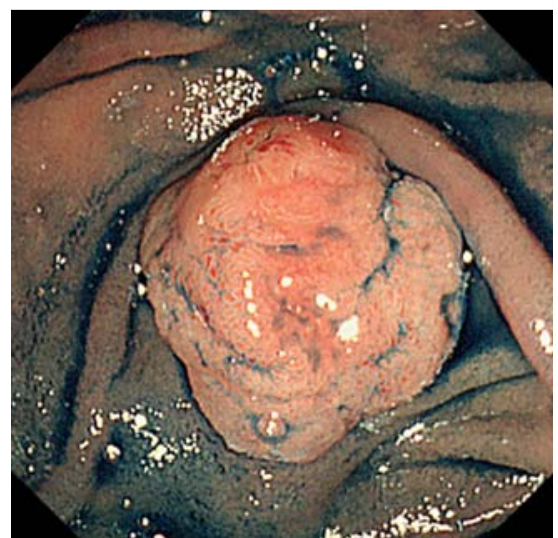

Fig. 1 Image during side-viewing duodenoscopy showing a tumor of the major duodenal papilla.

also showed the involutions of the mucosal folds while the muscle layer remained circular, as with the underwater technique [1].

Gel immersion endoscopic papillectomy (GI-EP) was chosen as the treatment with the patient's agreement and sufficient informed consent. An auxiliary injection cap (BioShield irrigator; US Endoscopy, Ohio, USA) was used to allow the operative channel to remain free, and Viscoclear was injected before and during GI-EP. En bloc papillectomy was

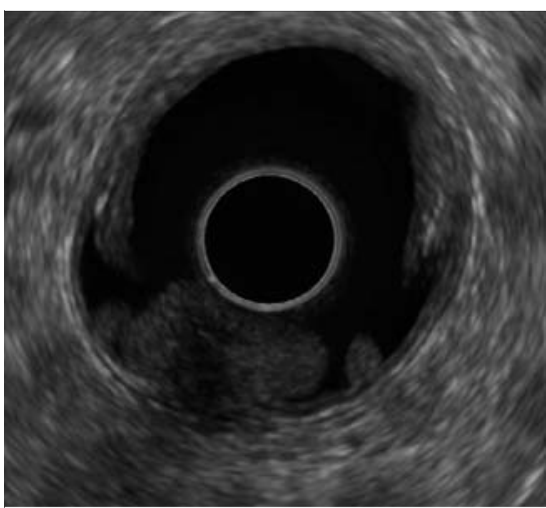

- Fig. 2 Endoscopic ultrasonography (EUS) image showing how the use of gel provided better acoustic coupling with the ampullary tumor without flattening, allowing gel immersion EUS to show an ampullary tumor without invasion of the duodenal muscularis propria or intraductal involvement, along with the involutions of mucosal folds while the muscle layer remained circular.

performed with a standard snare using a high frequency blended electric cutting current ( $\vee$ Fig.3a,b). After the resection, the specimen remained within the gel, the mild bleeding did not spread, and the visual field remained secure. A pancreatic stent was inserted, and the mucosal defect was closed using endo-
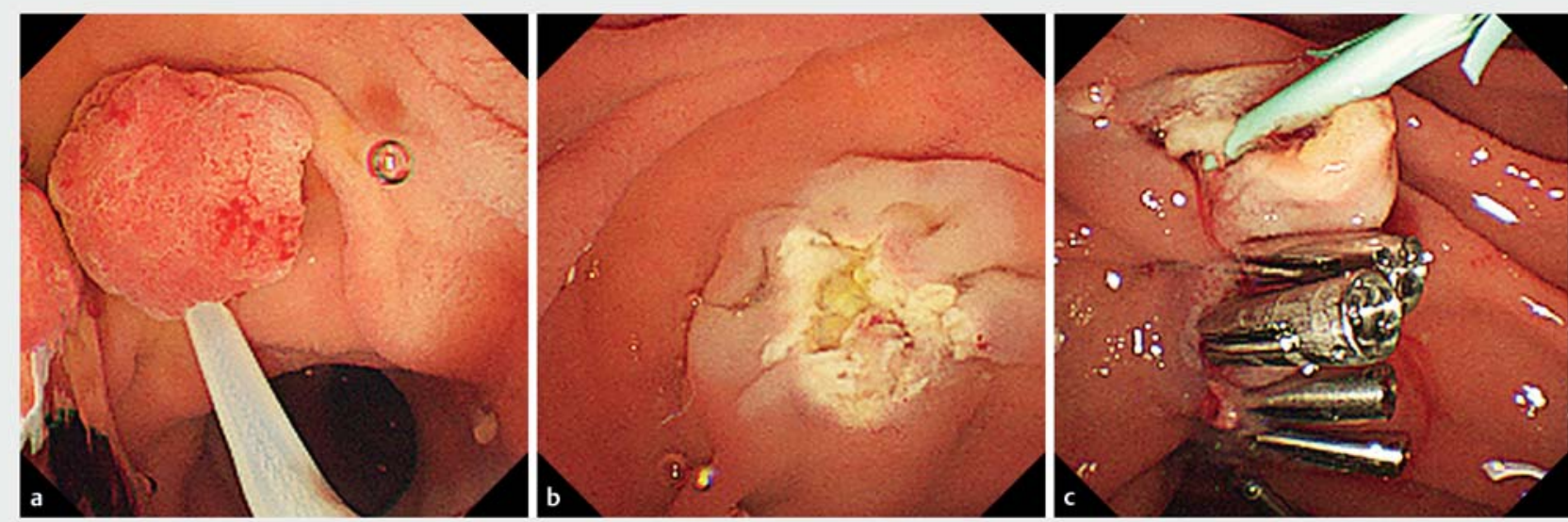

- Fig. 3 Endoscopic images showing: a the ensnared papilla during gel immersion papillectomy; $\mathbf{b}$ the appearance following papillectomy; c a pancreatic stent that was subsequently placed and closure of the mucosal defect with endoclips. 


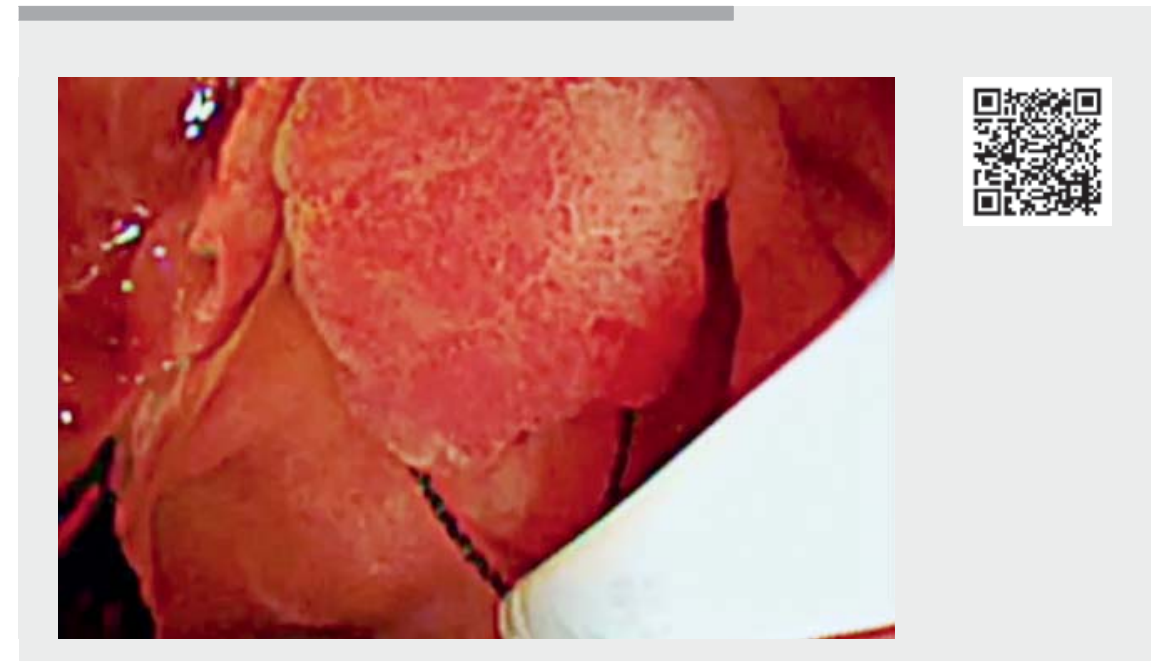

$\checkmark$ Video 1 The gel immersion technique is used successfully to examine an ampullary tumor using endoscopic ultrasonography and for treatment with endoscopic papillectomy.

clips (-Fig.3 c; > Video 1). No adverse events occurred and histopathological findings revealed a tubular adenoma with negative margins.

GI-EUS and GI-EP may be useful for the examination and treatment of ampullary tumors.

Endoscopy_UCTN_Code_TTT_1AS_2AD

\section{Competing interests}

Dr. Katanuma has received speaker's fees from Olympus Co., Tokyo, Japan. The remaining authors declare that they have no conflict of interest.

The authors

\section{Haruka Toyonaga $\odot$, Kuniyuki Takahashi, Toshifumi Kin, Tsuyoshi Hayashi, Akio Katanuma}

Center for Gastroenterology, Teine Keijinkai Hospital, Hokkaido, Japan
Corresponding author

\section{Haruka Toyonaga, MD}

Center for Gastroenterology, Teine-keijinkai Hospital, 1-40-1-12 Maeda, Teine-ku,

Sapporo 006-8555, Japan

toyonaga.pc@gmail.com

\section{References}

[1] Binmoeller KF, Weilert F, Shah J et al. "Underwater" EMR without submucosal injection eo). Gastrointest Endosc 2012; 75: 10861091

[2] Granata A, Curcio G, Ligresti D et al. Endoscopic ampullectomy: to inject or not to inject? The underwater technique. Endoscopy 2014; 46: E478-E479

[3] Keshava VE, Henien SR, Kumar AR. Endoscopic ampullectomy of a large neuroendocrine tumor using underwater EMR technique. VideoGIE 2020; 5: 314-317

[4] Yano T, Nemoto D, Ono K et al. Gel immersion endoscopy: a novel method to secure the visual field during endoscopy in bleeding for large sessile colorectal polyps (with vid- patients (with videos). Gastrointest Endosc 2016; 83: 809-811

[5] Miura Y, Yano T, Takezawa T et al. Gel immersion endoscopy simplifies hemostasis during endoscopic submucosal dissection using the pocket-creation method. Endoscopy 2018; 50: E294-E295

Bibliography

Endoscopy 2022; 54: E115-E116

DOI 10.1055/a-1408-0458

ISSN 0013-726X

published online 30.3.2021

(c) 2021. Thieme. All rights reserved.

Georg Thieme Verlag KG, Rüdigerstraße 14,

70469 Stuttgart, Germany

\section{ENDOSCOPY E-VIDEOS}

https://eref.thieme.de/e-videos

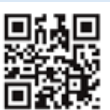

Endoscopy E-Videos is an open access online section, reporting on interesting cases and new techniques in gastroenterological endoscopy. All papers include a high quality video and all contributions are freely accessible online. Processing charges apply (currently EUR 375), discounts and wavers acc. to HINARI are available.

This section has its own submission website at https://mc.manuscriptcentral.com/e-videos 